\title{
Pendekatan Kognitif dalam Teori Kesehatan Mental Al-Balkhi: Psikologi Positif di Abad Keemasan Islam
}

\author{
Naufil Istikhari \\ Program Magister Psikologi, Fakultas Psikologi, Universitas Gadjah Mada, Yogyakarta
}

Abstrak. Penelitian ini berupaya menunjukkan pemikiran ilmuwan besar Muslim abad ke- 9 dan kontribusi teoretisnya dalam memadukan secara seimbang antara ranah gangguan mental dan kesehatan mental yang cenderung dikaji secara terpisah dalam psikologi Barat. Dalam risalahnya yang fenomenal, Mashâlih al-Abdân wa al-Anfus, Al-Balkhi mencoba menjembatani distingsi 'positif' dan 'negatif' dalam pendekatan klinis secara umum. Penelitian ini juga mengungkap metode terapi kognitif sebagai temuan orisinal Al-Balkhi di dunia Islam, suatu pendekatan yang dilakukan jauh sebelum psikologi modern lahir. Al-Balkhi juga menekankan posisi teoretisnya dalam kesehatan mental dengan pendekatan positif yang merupakan pionir dari psikologi Barat.

Kata kunci: Al-Balkhi, kesehatan mental, psikologi kognitif, psikologi positif

\section{Cognitive Approach in Al-Balkhi Mental Health Theory: Positive Psychology in the Islamic Golden Age}

Abstract. This research is to present a ninth-century Muslim polymath, Abu Zayd Al-Balkhi, and his theoretical contribution on the formation of the epistemological equilibrium between mental disorder and mental health which tends to be separated in the history of Western psychology. In his phenomenal treatise, The Sustenance of Body and Soul, Al-Balkhi made a bridge between 'positive' and 'negative' psychology in the common clinical approaches. This study also reveals the cognitive therapy approach as Al-Balkhi's authentic finding in the Islamic world, an approach well known long before modern psychology developed. Particular attention is paid to Al-Balkhi's emphasizes in positioning his theory of mental health, especially in a positive approach, in such as a pioneer of the Western psychological one.

Keywords: Al-Balkhi, cognitive psychology, mental health, positive psychology

Korespondensi: Naufil Istikhari. Email: naufilist@mailugm.ac.id 
Sejarah perkembangan psikologi, yang secara paradigmatis hampir semuanya klinis, memiliki kecenderungan tradisional untuk selalu memfokuskan kajiannya pada kelemahan dan kekurangan psikologis individu focused on psychological deficits and disability) (Carr, 2004). Fokus ini selaras dengan arti kata clinic yang di derivasi dari kata Yunani klinike, yang berarti "praktik medis di ranjang pasien yang sakit" (Maddux, 2002).

Tidak ada yang menyadari "bahaya dominasi" klinis ini sampai Martin Seligman terpilih menjadi ketua American Psychological Association (APA) pada 1998. Berawal dari momen epifani yang muncul ketika menemani anaknya bermain, Seligman tiba-tiba menyadari satu hal: psikologi lebih banyak memberi perhatian pada gangguan mental daripada potensi-potensi positif di dalam diri manusia (Seligman, 2002).

Seligman mulai mengalihkan fokus kajian psikologisnya dari yang semula hanya berkutat pada gangguan mental, penyimpangan seksual, trauma masa kanak-kanak, dan hal-hal negatif lainnya menjadi lebih dekat ke aspek-aspek positif dalam diri manusia. Menurut Seligman, psikologi bukan hanya studi tentang penyakit, kelemahan, dan keburukan individu, melainkan juga tentang kekuatan dan kebaikannya. Hal-hal positif dalam diri manusia seperti cinta, insight, optimisme, berpikir positif, dan sebagainya sangat penting untuk menjadi kajian psikologi agar ilmu ini tidak sekadar berurusan dengan penyembuhan individu yang sakit, tetapi juga- dan ini sebenarnya yang paling pentingmelakukan pencegahan dengan mengoptimalkan individu yang sehat (Carr, 2004; Seligman, 2002).

Menurut Seligman, psikologi telah mengabaikan dua misi terakhir dari tiga yang dicanangkan sebelum Perang Dunia II, yaitu penyembuhan penyakit mental (curing mental illness); membantu manusia lebih produktif dan hidup bermakna (helping all people to lead more productive and fulfilling lives); serta identifikasi dan pengembangan bakat tinggi (identifying and nurturing high talent). Dua yang terakhir ini secara prinsipal lebih cenderung tertarik melakukan asesmen terhadap individuindividu yang sehat serta bagaimana menjaga agar individu-individu tersebut tetap sehat dan produktif; inilah yang kemudian disebut psikologi positif (Alex Linley et al., 2006; Seligman, 2002).

Pilar paling fundamental yang menyangga psikologi positif adalah pikiranpikiran yang positif (Hope, 2011). Pikiran positif dalam kajian psikologi masuk pada ranah psikologi kognitif yang dalam terapannya mendemonstrasikan praktik terapi kognitif (cognitive therapy). Terapi kognitif, menurut Yaacob (2013) adalah tipe psikoterapi yang bertujuan membantu pasien atau klien untuk mengatasi kesulitan-kesulitan psikologis dengan cara mengubah dan memodifikasi disfungsi pikiran, perilaku, dan respons emosional. 
Psikologi kognitif sebenarnya berkembang dan tumbuh dari tradisi Behavioristik di satu sisi dan Gelstat di sisi lain. Itu artinya, psikologi kognitif baru menjadi disiplin ilmu dalam pengertian modern pada awal abad ke-20, sebelum Perang Dunia I. Namun, baru pada 1960-an, terapi kognitif dipakai secara luas hampir di seluruh dunia (Asch, 2002). Sejak 2000-an, psikologi kognitif lalu diadopsi ke dalam model-model pendekatan psikologi positif (Alex Linley et al, 2006).

Tren psikologi yang berkembang di Barat sedikit banyak memberi pengaruh terhadap perkembangan psikologi di dunia muslim, meskipun belakangan telah muncul kesadaran untuk melakukan "islamisasi psikologi" (Kertanegara, 2014; York Al-Karam, 2018). Akibat pengaruh tersebut, banyak di antara psikolog muslim sendiri yang tidak familier dengan kekayaan khazanah psikologi yang berkembang di dunia Islam jauh sebelum psikologi modern lahir (Haque, 2004). Padahal, banyak sekali konsep psikologi yang dapat dikembangkan dan digali dari khazanah literatur klasik Islam, termasuk konsep psikologi positifyang banyak dijumpai di dalam ajaran tasawuf (Kertanegara, 2014).

Salah satu khazanah yang telat diketahui adalah teori kognitif yang dikembangkan oleh Abu Zayd Al-Balkhi pada abad ke-9. Disebut telat karena karya monumentalnya baru ditemukan dan dikodifikasikan pada awal 1990-an oleh filolog Jerman, Fuat Sezgin, saat psikologi kognitif di Barat sudah berkembang, yang kemudian disusul psikologi positif setelahnya. Mekipun secara teoretis berkembang secara terpisah, antara terapi kognitif dan psikologi positif memiliki akar dan landasan yang sama, yaitu meningkatkan kualitas hidup dengan mengeliminasi pikiranpikiran negatif (Hope, 2011). Kesamaan landasan tersebut, sebagaimana diungkap artikel ini, telah eksplisit di dalam karya AlBalkhi.

Penelitian Haque (2004) tidak ragu menyebut Al-Balkhi sebagai psikolog kognitif pertama, bahkan dalam pengertiannya yang modern (Badri, 2013), sebab Al-Balkhi pada waktu itu telah mampu membedakan secara tegas antara neurosis dan psikosis serta memiliki konsep teoretis tentang bagaimana terapi kognitif dapat digunakan untuk menyembuhkan gangguan psikologis tersebut.

Kendati Al-Balkhi menyebut dan mengklasifikasi jenis gangguan psikologis tertentu, ia tidak memiliki pretensi kuat terhadap pendekatan klinis. Hasil penelitian Rania Awaad dan Sara Ali yang berjudul “Obsessional Disorders in Al-Balkhi's 9th Century Treatise: Sustenance of the Body and Soul" (Awaad \& Ali, 2015) dan "A Modern Conceptualization of Phobia in Al-Balkhi's 9th Century Treatise: Sustenance of the Body and Soul" (Awaad \& Ali, 2016) seolah-olah memang menunjukkan pendekatan Al-Balkhi murni klinis, tetapi sebenarnya tidaklah demikian. Rania Awaad dan Sara Ali sekadar mengambil salah satu fokus kajian dan kemudian berupaya 
menegaskan bahwa klasifikasi Al-Balkhi terhadap obsesif kompulsif dan fobia sangat mirip dengan yang ada di dalam DSM-V. Di dalam Mashâlih al-Abdân wa al-Anfus, Al-Balkhi sebenarnya jauh lebih banyak membicarakan tentang kesehatan mental daripada gangguan mental.

Dua penelitian Rania Awaad dan Sara Ali di atas, sejauh telusur peneliti, merupakan (mungkin) satu-satunya penelitian paling awal berbahasa Inggris yang secara khusus membicarakan kerangka teoretis Al-Balkhi dalam perspektif klinis. Ini tentu akan melahirkan miskonsepsi terhadap pendekatan keseluruhan Al-Balkhi di dalam risalahnya jika tidak memeriksa langsung sumber aslinya. Penelitian Musfihin (2019), meskipun cukup berimbang, lebih layak disebut resensi terhadap buku Al-Balkhi daripada kajian sistematis terhadap aspek tertentu yang menjadi ciri khas jurnal pemikiran.

Penelitian ini berupaya "meluruskan" serta "menunjukkan" secara imbang dan presisi pendekatan kognitif Al-Balkhi terhadap kesehatan mental-yang cenderung berorientasi positif daripada klinis-melalui penyandingan dan pembandingan langsung dengan tema-tema pokok teori kognitif modern. Tidak hanya itu, penelitian ini juga akan menunjukkan secara gamblang bagaimana pendekatan kognitif Al-Balkhi sangat relevan untuk dikatakan sebagai prototipe paling awal psikologi positif dari dunia Islam.

\section{Metode}

Metode penelitian yang digunakan di sini adalah jenis kualitatif berbasis telaah pustaka (library research) dengan mengacu pada sumber primer berbahasa Arab karya Abu Zayd Sahl Al-Balkhi, Mashâlih al-Abdân wa alAnfus. Sedangkan pisau analisis yang digunakan adalah fenomenologi hermeneutis (hermeneutic phenomenology). Fenomenologi hermeneutis berakar pada konsepsi ontologis Martin Heidegger yang berbeda dari fenomenologi transendental Edmund Husserl (Kafle, 2013). Cohen mengartikan fenomenologi hermeneutis sebagai metode untuk memahami teks atau memahami dunia fenomenologis seseorang melalui teks yang ditinggalkannya. Pendekatan ini bertujuan untuk menciptakan pemahaman mendalam terhadap fenomena (dalam hal ini makna kesehatan mental pada abad ke-9) dengan menitikberatkan pada pengungkapan/ penyingkapan daripada akurasi (Hein \& Austin, 2001; Kafle, 2013). Mengutip van Mannen, Hein dan Austin mengemukakan, dalam fenomenologi hermeneutis, peneliti harus mampu "membawa suatu pengertian baru terhadap apa yang individu ungkapkan di dan lewat kata-kata", termasuk di dalamnya adalah merefleksikan tema-tema esensial; mendeskripsikan fenomena melalui teks; dan menyeimbangkan konteks penelitian yang terdiri dari bagian-bagian dan keseluruhan (Hein \& Austin, 2001). 
Dalam artikel ini, peneliti akan merujuk dan menampilkan kutipan teks asli dalam karya Al-Balkhi yang relevan dengan fokus penelitian, kemudian memberikan interpretasi semantik terhadap teks tersebut sambil menghadirkan konteks diskursus yang berkembang di dalam psikologi modern.

\section{Hasil}

\section{Kesehatan mental di era keemasan Islam}

Sejumlah sejarawan umumnya menyebut abad ke-9 sampai ke-11 sebagai era keemasan Islam. Hal ini ditandai dengan keberadaan Baitul Hikmah sebagai pusat penelitian, penerjemahan, dan sekaligus sebagai perpustakaan terbesar yang pernah dimiliki Islam. Di bawah kepemimpinan Harun Al-Rasyid dan Al-Ma'mun, Baghdad menjadi pusat pendidikan terbaik di dunia yang menarik sarjana-sarjana dari Eropa berdatangan ke sana dan belajar ilmu pengetahuan yang berasal dari Yunani, India, Suriah, dan Persia. Sarjanasarjana lulusan Baghdad ini kemudian menerjemahkan karya-karya Yunani berbahasa Arab ke dalam bahasa Latin (Haque, 2004; Nasr, 1970).

Pada masa itu, kekhalifahan Abbasiyah sudah memiliki rumah sakit umum. Rumah sakit pertama di dunia yang menyediakan bangsal khusus pasien sakit jiwa dibangun pada 705 di Baghdad, menyusul Maroko beberapa tahun kemudian, dan di Kairo pada 800 (Mohamed, 2012). Keberadaan rumah sakit jiwa di era keemasan Islam mengindikasikan secara faktual bahwa pada masa itu konsep "gangguan jiwa" dan "kesehatan mental" bukan lagi sekadar spekulasi filosofis seperti yang berkembang di Yunani (Haque, 2004), melainkan telah menjadi konsep praksis yang berdasar pada postulat teoretis yang teruji (Kertanegara, 2014). Namun, teori dan praktik terapi yang berasal dari masa-masa itu tidak banyak dikenal di dunia Barat (dan juga di dunia Muslim) hingga sekarang karena di samping minimnya terjemahan teks klasik ke dalam bahasa Inggris juga disebabkan banyaknya teks-teks penting tersebut yang hilang dan tidak ditemukan salinannya sampai sekarang (Nasr, 1970).

Perhatian terhadap kesehatan mental sudah tercurah sejak pemerintahan Khalifah AlManshur (712-775) dan terus berlanjut hingga kemunduran Dinasti Abbasiyah pada abad ke13. Banyaknya penerjemahan karya-karya asing ke dalam bahasa Arab turut memberi pengaruh besar terhadap teori kesehatan mental yang berkembang di dunia Islam. Namun, pada masa-masa ini, sudah terbangun konsep univokal tentang kesehatan mental yang tidak bisa dipisahkan begitu saja dengan kesehatan jasmani. Seorang dokter terkenal bernama Yuhana ibn Masawaih yang banyak menulis buku panduan praktis tentang kesehatan menekankan secara gamblang bahwa kesehatan jasmani hanya mungkin dicapai apabila unsur-unsur ruhani (psikologis) juga sehat (mizâj al-jism tâbi' li akhlâq al-nafs). Karena itu, tulis Yuhana ibn Masawaih, seorang 
dokter harus mampu menegakkan diagnosis tidak saja secara fisik, tetapi juga secara psikologis (Mishry, 2005).

Paruh kedua abad ke-8 ditandai dengan adaptasi secara literer terhadap konsep-konsep kedokteran Yunani maupun Mesir (Alexandria). Teori Galen tentang empat tipe kepribadianyang sejatinya berasal dari Hippokratesmenjadi familier di periode ini. Al-Balkhi hidup pada periode berikutnya yang sudah mencapai kematangan ('ash al-nadhûj). Periode ini ditandai dengan empat hal, yaitu (a) berkembangnya paradigma demonstratif dan teoretis di samping empiris dan praksis; (b) munculnya kajian dan karya yang sistematis dalam bidang kedokteran; (c) klasifikasi yang sistematis terhadap teks-teks Yunani; dan (d) munculnya kritik dan modifikasi terhadap model-model Yunani (Mishry, 2005).

Pada periode kematangan ini, kajian tentang ilmu jiwa masih menjadi satu disiplin dengan kedokteran, dan masih akan berlanjut hingga beberapa abad setelahnya. Dokter yang bekerja di rumah-rumah sakit Baghdad lebih tepat disebut psikiater daripada dokter ataupun ahli jiwa (psikolog) saja (Mishry, 2005; Nasr, 1970). Hal ini dapat dilihat dari definisi kedokteran yang masyhur kala itu. Kedokteran didefinisikan sebagai “'ilmun yata'arrafu minhu ahwâl al-badani wa al-nafsi, li yahfidza alshihhata hâshilatan, wa yastaraddahâ zâilatan." Jadi, asesmen dan diagnosis kesehatan pada waktu itu meliputi tubuh dan psikis sekaligus.

Secara skematis, periode perkembangan kedokteran (ingat, pada masa itu ilmu jiwa dan kesehatan mental masih satu rumpun dengan kedokteran) pada Dinasti Abbasiyah diawali dengan pembangunan rumah-rumah sakit di beberapa wilayah dan penerjemahan karyakarya kedokteran Yunani, Alexandria, dan Persia ke dalam bahasa Arab; periode berikutnya merupakan awal kelahiran ilmuwan-ilmuwan yang kritis terhadap teori yang berasal dari Yunani dan sampai pada tahap melakukan beberapa modifikasi terhadapnya; dan periode terakhir ditandai populernya metode eksperimen (tajrîby) yang dalam beberapa aspek cukup independen dari bayang-bayang Yunani (Kertanegara, 2014; Nasr, 1970). Periodisasi ini tidak mengacu pada kronologi waktu secara linear, tetapi lebih kepada tahap pencapaian intelektual, karena perkembangan di daerah-daerah yang lebih jauh dari pusat kekuasaan Islam (Baghdad) tidak secepat yang terjadi di pusat. Al-Balkhi sendiri tumbuh pada periode kedua, dan berhasil memulai periode ketiga lewat karyanya.

\section{Gambar 1}

Periodisasi Kedokteran Islam

\begin{tabular}{|c|c|c|c|}
\hline $\begin{array}{c}\text { Periode } \\
\text { Penerjemahan dan } \\
\text { Rumah Sakit Iiwa }\end{array}$ & $\begin{array}{c}\text { Periode } \\
\text { Periode Modifikasi } \\
\text { Teori dari Yunani } \\
\end{array}$ & $\begin{array}{c}\text { Eksperimen dan } \\
\text { Kodifikasi }\end{array}$ \\
\hline
\end{tabular}


Uraian di atas sedikit dapat menggambarkan bagaimana perkembangan konsep dan posisi kesehatan mental di era keemasan Islam, khususnya dalam kurun ketika Al-Balkhi (849-943) hidup. Al-Balkhi hidup di masa ketika otonomi daerah menguat dan beberapa kerajaan kecil di bawah kekuasaan kekhalifahan Abbasiyah bermunculan. Khurasan, daerah Al-Balkhi lahir, berdiri Dinasti Samaniyah yang rajanya dikenal mencintai ilmu-ilmu pengetahuan dan rakyatnya bebas belajar ilmu apa saja yang mereka minati. AlBalkhi tumbuh besar dalam kondisi sosialpolitik semacam ini, sehingga ia menguasai pelbagai disiplin ilmu pengetahuan yang meliputi geografi, sejarah, filsafat, fikih, ilmu tafsir, linguistik, astronomi, fisiologi, dan tentu saja, kedokteran. Al-Balkhi belajar ilmu-ilmu kedokteran Yunani dari Al-Kindi di Baghdad. Sejauh catatan yang ada, Al-Balkhi menulis lebih dari 64 kitab dengan spesifikasi kajian yang berbeda-beda, tetapi sayangnya hanya dua buah yang tersisa, yaitu Shuwar al-Aqâlîm (tentang geografi dan astronomi) dan Mashâlih al-Abdân wa al-Anfus (tentang kesehatan mental).

Buku Mashâlih al-Abdân wa al-Anfus terdiri dari dua bagian. Bagian pertama berisi 14 bab, sedangkan bagian kedua berisi 8 bab. Pokok bahasan dalam penelitian ini mengacu pada bagian kedua yang khusus menjelaskan kesehatan mental (mashâlih al-anfus).

\section{Teori kesehatan mental Al-Balkhi}

Pada bab pertama bagian kedua Mashâlih al-Abdân wa al-Anfus, Al-Balkhi membuka pembahasannya dengan membuat satu rumusan hipotetis bahwa oleh karena manusia terdiri dari tubuh dan jiwa, maka keduanya dapat sehat atau sakit dan kuat atau lemah. Sebagaimana tubuh yang dapat terserang penyakit sehingga mengalami penurunan kualitas kesehatan, begitupun dengan jiwa. Namun, berbeda dari kesehatan badan yang lebih mendapat perhatian banyak orang, perhatian terhadap kesehatan mental cukup minim. Ini, tulis Al-Balkhi, disebabkan oleh kondisi psikologis seseorang yang dalam kadar tertentu dapat menolak terhadap sumber-sumber yang mendatangkan tekanan dan rasa sakit terhadap jiwa. Al-Balkhi mengistilahkan mekanisme ini sebagai "madfû' ilâ $m \hat{a}$ yata'adzdzâ bihi".

Sumber segala tekanan adalah keinginan dan harapan yang muncul di dalam pikiran, sementara keduanya tidak mesti selalu menjadi kenyataan. Individu yang sehat mengerti bagaimana mengelola hasrat, keinginan, dan harapan sehingga ia memiliki mekanisme respons emosi yang lebih baik terhadap kondisi buruk yang tidak diinginkan. Secara lebih lugas, AlBalkhi mendefinisikan kesehatan mental sebagai:

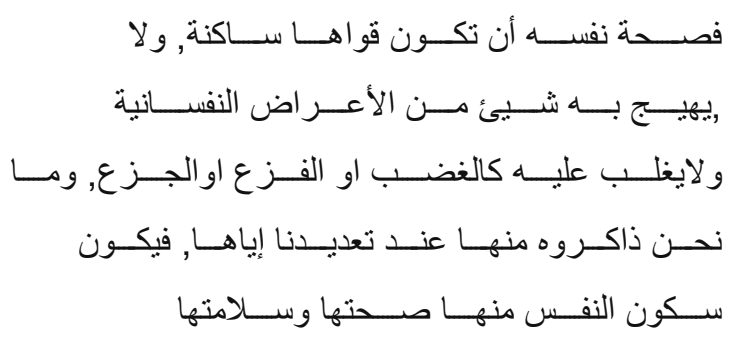


[Sehat secara mental berarti adanya keseimbangan energi emosi, sehingga ia tidak terdikte oleh penyakit mental dan tidak terkalahkan oleh pengaruh emosi negatif seperti agresi, panik, depresi dan apa pun yang dapat mengganggu pikiran.

Dengan cara mengatasi dengan baik emosi negatif, jiwa akan sehat dan tenang ... ]

Deskripsi di atas menjelaskan secara eksplisit bahwa sehat mental adalah kondisi keseimbangan energi psikis yang terjaga dengan stabil dan bebas dari hal-hal yang dapat menginfeksi jiwa sehingga ia tetap dalam kondisi yang tenang dan stabil (Al-Balkhi, 2005). Meski demikian, Al-Balkhi tidak lantas mengabaikan energi fisik, sebab yang disebut terakhir ini merupakan bagian tidak terpisahkan dari energi psikis. Hubungan resiprokal (isytibâk) di antara keduanya adalah syarat yang memungkinkan tercapainya kesehatan mental. Konsep keseimbangan (adjustability, balance) adalah kata kunci untuk memahani teori kesehatan mental Al-Balkhi (Deuraseh \& Talib, 2005; Musfihin, 2019).

Definisi Al-Balkhi memiliki kemiripan dengan definisi WHO yang menyebutkan kesehatan mental sebagai ... a state of complete physical, mental and social well-being and not merely the absence of disease or infirmity. Kesehatan mental dalam pengertian modern harus memenuhi prinsip keseimbangan antara bagian-bagian kesehatan (integral part of health); bukan sekadar tidak sakit (more than the absence of mental illness); terkait dengan kesehatan fisik dan perilaku (intimately connected with physical health and behaviour) (Herrman, 2005).

Selain itu, Al-Balkhi cenderung memahami kesehatan mental secara empiris dengan perspektif kognitif (Badri, 2013). Hal itu dapat dilihat dari, misalnya, identifikasi AlBalkhi terhadap faktor-faktor yang menyebabkan terjadinya ketidakseimbangan mental sehingga pada gilirannya individu terpapar sakit mental. Ada dua faktor penting yang disebut Al-Balkhi agar individu mencapai keadaan sehat mental, yaitu mampu menjaga diri dari faktor eksternal (an tushâna al-a'râdh al-khârijah) yang terserap melalui pancaindra dan faktor internal (an tushâna al-a'râdh aldâkhilah) yang melibatkan proses kognitif. Sisi empirisnya adalah bahwa kesehatan mental seringkali terhambat justru karena penyerapan indra penglihatan dan pendengaran yang salah penyesuaian (maladjusment). Hampir tidak ada penyebab ketidakseimbangan elemenelemen mental tanpa melalui persepsi indriawi, terutama penglihatan dan pendengaran (AlBalkhi, 2005; Thaha, 2011).

Untuk mencapai kondisi mental yang sehat, menurut Al-Balkhi, seseorang pertamatama harus mengetahui struktur jiwanya sendiri. Struktur di sini berarti kadar kemampuan jiwa di dalam meresepsi apa pun yang didapat dari stimulus indrawi. Setiap manusia memiliki kadar kemampuannya sendiri dalam menerima dan merespons keadaan yang datang dari luar. Masalah yang sama memiliki dampak yang 
berbeda bagi seseorang. Itu terjadi karena hati memiliki potensi untuk lapang atau sempit dan kuat atau lemah. Orang yang mengetahui kadar kemampuan hati/jiwanya akan selektif di dalam menerima dan merespons apa pun yang datang dari luar. Al-Balkhi kemudian menegaskan:

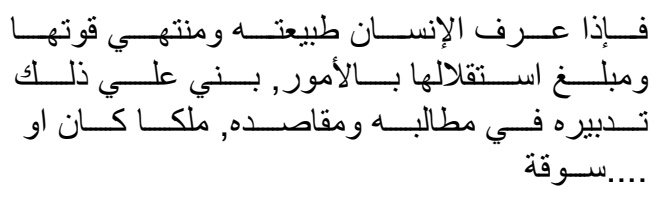

[Apabila manusia mengetahui karakter,

batas kekuatan, dan tingkat resiliensi

dirinya terhadap pelbagai persoalan, maka

mereka akan dapat mengatur dan

menempatkan respons emosi secara lebih

baik ...]

Dengan kata lain, Al-Balkhi memandang bahwa apabila seseorang sudah mengetahui watak dan batas kemampuannya di dalam setiap usaha meraih dan menerima setiap persoalan, maka selayaknya bagi mereka menciptakan regulasi dan efikasi diri agar mereka dapat mengontrol dengan baik apa yang hendak dicapainya itu lengkap dengan kesiapan mental untuk menerima kemungkinan terburuk yang bakal terjadi. Artinya, kesehatan mental menurut Al-Balkhi dapat dicapai apabila individu telah mampu mengenal dan mengetahui batas kemampuan dirinya sehingga ia mampu melakukan regulasi dan kontrol atasnya.
Terdapat dua konsep utama kesehatan mental Al-Balkhi, yaitu "menjaga kesehatan mental" dan "membentuk kesehatan mental"; keduanya saling terkait satu sama lain, meskipun konsep pertama bersifat defensif, sedangkan konsep kedua bersifat proaktif. Dalam posisi defensif, seseorang perlu mengelola tekanan yang datangnya dari luar dan dari dalam sekaligus. Tekanan yang datang dari luar seyogiyanya disaring dan diseleksi sesuai dengan kapasitas emosi. Hal itu dapat terwujud apabila pikiran tidak berlebihan dalam menilai. Pikiran memiliki kemampuan untuk berimajinasi dan melakukan pengandaian-pengandaian. Dan ini bersifat internal. Dengan cara mengendalikan pikiran dan kemampuan imajinatif inilah tekanan yang datang dari dalam dapat dikelola dengan baik. Untuk membentuk mental yang sehat, individu perlu proaktif mencari pengetahuan yang lengkap dan berimbang dari luar. Dengan cara ini, ia tidak akan mudah reaksioner dan emosional terhadap isu-isu yang datang dari luar. Dan di saat yang sama, seseorang juga perlu merefleksikan pengetahuan tentang batas-batas emosional dirinya dengan pengetahuan yang datang dari luar, sehingga ia akan dapat mengembangkan masukan dari luar menjadi perbaikan internal terhadap sifat-sifat kedirian. 


\section{Gambar 2}

Skema Kesehatan Mental Al-Balkhi

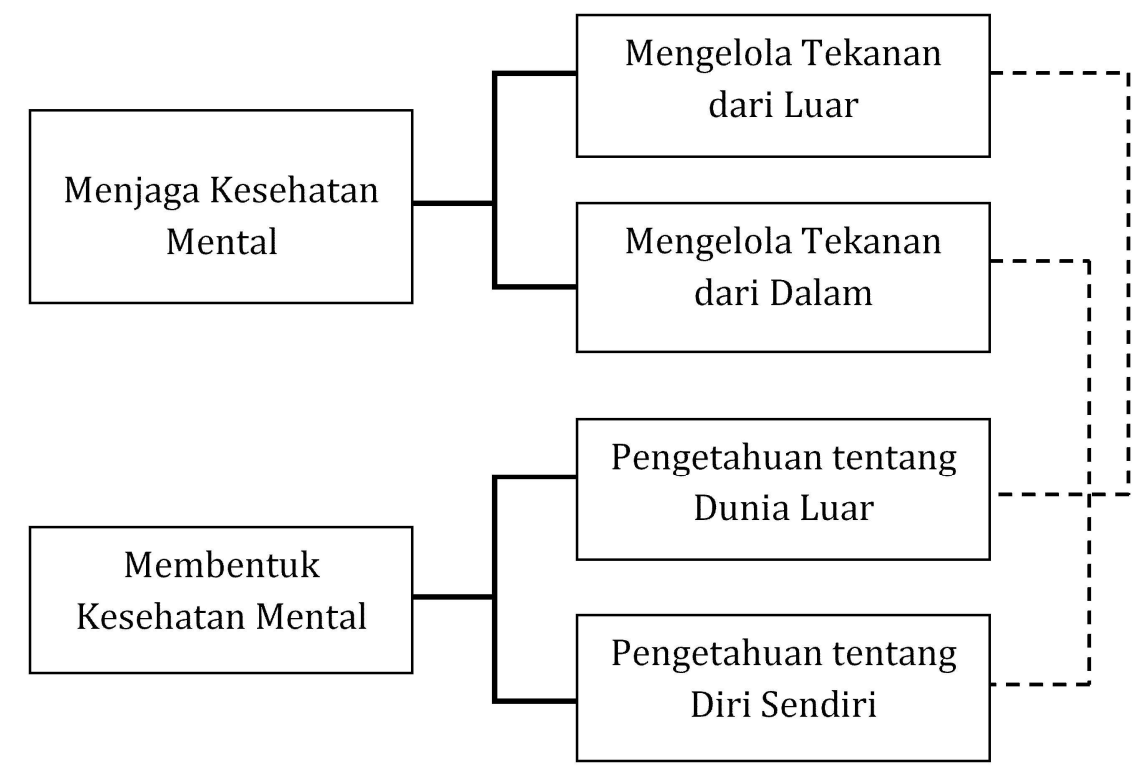

Di sini terlihat jelas bahwa Al-Balkhi mengorelasikan secara positif antara kontroldiri dan kesehatan mental. Hubungan ini hanya dapat terwujud apabila didukung oleh pengetahuan yang baik tentang emosi diri sendiri dan juga mengetahui dengan baik kondisi-kondisi di luar diri yang melingkungi. Menariknya, korelasi positif ini tetap terbukti kebenarannya hingga sekarang. Penelitian Boals et al (2011), misalnya, menyebutkan bahwa memang ada korelasi positif antara kontrol-diri dan kesehatan mental dengan gaya coping sebagai variabel antara. Semakin individu memiliki kontrol-diri tinggi semakin baik pula strategi coping-nya. Strategi coping yang baik menjadi faktor penting yang memengaruhi kesehatan mental; dan sebaliknya, mental yang sehat dapat memengaruhi efektivitas coping.

\section{Pendekatan kognitif Al-Balkhi}

Al-Balkhi menyebut empat gangguan emosional yang sering menyebabkan ketidakseimbangan antara fungsi tubuh dan jiwa, yaitu agresi-marah (al-ghadab), takut/ fobia-panik (al-khauf wa al-faza'), sedihdepresi (al-hazn wa al-jaza'), dan obsesifkompulsif (al-wasâwis al-shadr). Klasifikasi tersebut didasarkan atas data-data sosiohistoris yang menggejala pada waktu itu. Menariknya, seperti yang telah diurai sedikit pada subbab sebelumnya, Al-Balkhi selalu mendiagnosis setiap simtom gangguan fisik atau psikis dengan mengasosiasikannya pada dua faktor yang sama-sama penting, yaitu stimulus dari luar dan persepsi dari dalam. Subbab ini akan mempertajam pembahasan faktor yang kedua.

Setiap stimulus indrawi, tulis Al-Balkhi, akan masuk dan mengendap di dalam pikiran. 
Pikiran bertanggung jawab menerima, mengolah, memproduksi, dan merespons balik terhadap stimulus yang datang dari luar. Di sinilah letak pendekatan kognitif Al-Balkhi terbukti orisinal (Badri, 2013). Secara eksplisit, Al-Balkhi menulis:

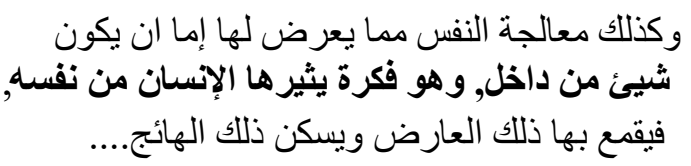

[Demikian juga dengan terapi jiwa yang dapat dilakukan dari dalam diri sendiri, yaitu dengan mengelola pikiran yang dapat memengaruhi emosi, sehingga ia dapat menjadikannya positif dan membuang pikiran negatif ...]

Berangkat dari asumsi teoretis tersebut, lalu Al-Balkhi secara konsisten mengembangkan teori pikiran (kognitif) untuk pengembangan terapinya. Hal itu dapat dilihat dari setiap poin rekomendasi terapeutik أن" Al-Balkhi yang selalu diawali dengan frasa

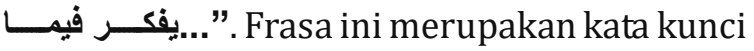
pendekatan kognitif Al-Balkhi di dalam seluruh bangunan teoretisnya. Dalam proses terapi, misalnya, Al-Balkhi menawarkan semacam "penyangkalan-penyangkalan kognitif" untuk mengembalikan stabilitas mental yang terkorupsi dan tercemari oleh pikiran. "Penyangkalan kognitif" yang dimaksud adalah berusaha memikirkan seuatu yang merupakan kebalikan dari perasaannya (AlBalkhi, 2005). Al-Balkhi menyebutnya: al-ilâj bi al-dhid atau sama dengan reciprocal inhibition-nya Joseph Wolpe (Haque, 2004).
Dalam risalahnya, Al-Balkhi selalu mensyaratkan "pengetahuan" sebagai prakondisi menuju mental yang sehat. Subbab sebelumnya telah menjelaskan bagaimana seseorang disyaratkan memiliki pengetahuan terhadap struktur jiwanya sendiri. Syarat lainnya yang belum disebutkan di atas adalah pengetahuan terhadap kondisi lingkungan (ma'rifah al-insân li ahwâl al-dunyâ) secara lengkap. Lingkungan yang dimaksud Al-Balkhi merujuk pada lingkungan fisik (kamar mandi, saluran air, tata ruang, dlsb.) serta lingkungan nonfisik (watak masyarakat, kondisi sosial, gaya hidup, dlsb.). Pengetahuan terhadap lingkungan menjadi penting karena dengan bekal pengetahuan tersebut seseorang dapat mengontrol dan memanaj dengan baik hasrat yang berasal dari tuntutan lingkungan tadi (Mishry, 2005).

Di beberapa bab dalam Mashâlih al-Abdân wa al-Anfus, Al-Balkhi dengan eksplisit menyebut terapinya sebagai "المعالجـــــة المعرفيــــــ" (terapi kognitif). Terapi ini sangat sentral karena dengan model ini Al-Balkhi dapat berfokus pada upaya menghilangkan ketidaktahuan terhadap hakikat hal-ihwal (izâlatu al-jahl bi haqîqat al-asyyâ'). Ketidaktahuan terhadap proporsi segala halihwal atau isu yang berkembang menyebabkan individu mudah tergoda dan terpengaruh oleh orang lain, sehingga ia kehilangan independensi. Sebaliknya, Al-Balkhi menganjurkan setiap orang untuk melihat ke dalam dirinya sendiri tanpa cepat terpengaruh oleh keinginan dan kemauan orang lain terhadapnya. Individu yang 
independen tidak terbentuk dari ruang kosong. Ia mesti memiliki pengetahuan yang utuh tentang diri dan lingkungannya.

Ketidaktahuan menurut Al-Balkhi bukan semata tidak tahu dalam arti bodoh dan tidak memiliki pemikiran sama sekali, tetapi malah terkadang memiliki pengetahuan, tetapi keliru dan tidak utuh tentang diri dan lingkungannya. Dasar dari pengetahuan yang dianjurkan Al-Balkhi adalah pengetahuan yang benar atau rasional (al-ma'rifah almanthiqy). Hanya dengan memelihara pengetahuan yang benar dan logis mengenai diri dan lingkungannya, seseorang mampu mencapai kesehatan mental. Kerangka teori kesehatan mental Al-Balkhi yang demikian itu mendapat justifikasi empiris di dalam psikologi kognitif modern. Konsep pengetahuan diri Al-Balkhi tidak ada bedanya dengan pengetahuan diri (self-knowledge) dan artikulasi pengetahuan diri (articulation of self-knowledge) yang menjadi lema dalam psikologi kognitif modern. Hanya saja lema tersebut, dalam psikologi kognitif modern, menjadi semakin terspesifikasi ke dalam, misalnya, konsekuensi dari fokus diri (selffocus) yang seterusnya memengaruhi regulasi diri (self-regulation) (Asch, 2002).

\section{Gambar 3}

Skema Pendekatan Kognitif Al-Balkhi

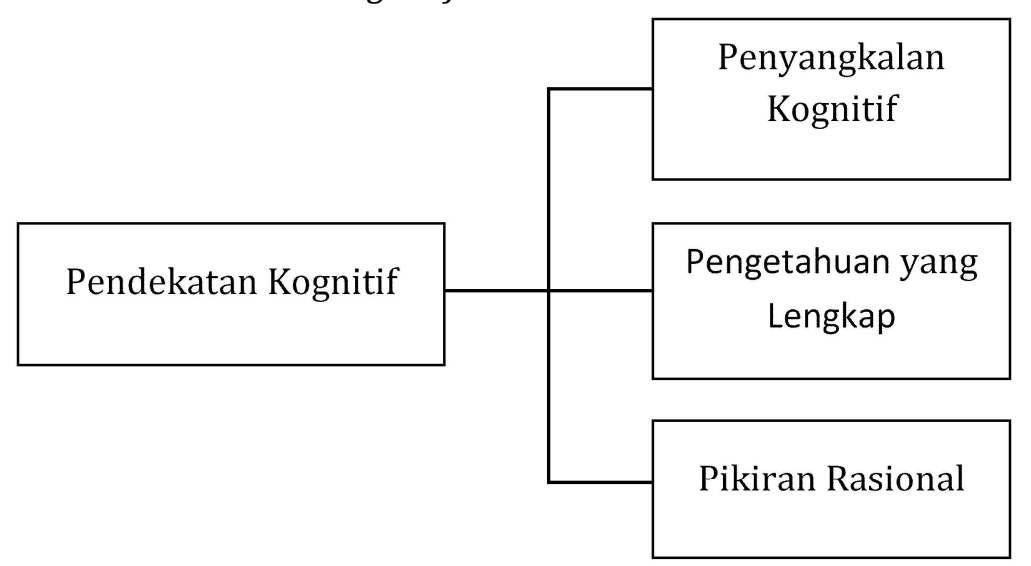

Terapi Al-Balkhi bergantung pada pemenuhan pikiran yang seimbang (Musfihin, 2019). Dalam sejumlah kasus yang ditemui AlBalkhi, misal waswas (obsesif kompulsif), alihalih menghubung-hubungkannya dengan adanya gangguan atau bisikan dari setan, murid Al-Kindi yang satu ini lebih tertarik menyebut pikiran yang terkorup atau pikiran yang terdistorsi (al-afkâr al-khathîah) sebagai penyebab kewaswasan seseorang (Awaad \& Ali, 2015). Memang tidak mustahil makhluk gaib yang bernama setan dapat mengganggu dan menggoda manusia seperti yang secara eksplisit disebutkan dalam Al-Quran, tetapi AlBalkhi, dengan pendekatan kognitifnya, sama sekali tidak menghubung-hubungkan dengan 
doktrin ini. Al-Balkhi konsisten fokus pada pemeriksaan pikiran-pikiran yang tidak sesuai dengan prinsip rasionalitas. Makanya, dalam salah satu sesi tarapinya, Al-Balkhi menganjurkan adanya dialog dengan orangorang ahli hikmah (Al-Balkhi, 2005).

\section{Orientasi positif Al-Balkhi}

Autentisitas pendekatan kognitif AlBalkhi ternyata juga ditopang kukuh oleh orientasi positif yang menjiwai keseluruhan kerangka teoretisnya. Kata mashâlih dalam judul risalah yang ditemukan Fuat Sezgin itu menyiratkan orientasi positifnya secara tidak langsung. Jenis-jenis gangguan mental yang disebut Al-Balkhi sebagai al-a'râdh alnafsâniyyah hanyalah sebagai bentuk acuan informatif untuk mengetahui makna kesehatan secara keseluruhan. Sehat dalam terminologi AlBalkhi merujuk pada sehat jasmani (fisis) dan ruhani (psikis) secara simultan. Mustahil memprioritaskan salah satu dengan mengabaikan yang lainnya. Dengan cara itulah Al-Balkhi mendemonstrasikan pemikirannya tentang ilmu jiwa manusia ('ilm al-nafs).

Bukti bahwa Al-Balkhi memiliki orientasi positif dalam pendekatan kognitifnya adalah pernyataannya di dalam bab terakhir bagian pertama Mashâlih al-Abdân wa al-Anfus:

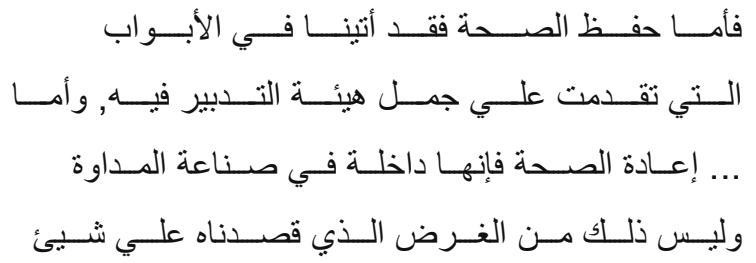

[Tips-tips menjaga kesehatan mental telah saya uraikan dalam beberapa cara pada bab-bab sebelumnya, sedangkan menyembuhkan penyakit mental bergantung pada dosis-dosis tertentu yang lebih rumit, ... tetapi bukan itu yang menjadi tujuan utama teori saya]

Pernyataan tersebut jelas sekali berorientasi positif dan tidak memiliki pretensi klinis meskipun fokus kajian Awaad \& Ali (2015, 2016) menunjukkan seolah-olah pendekatan AlBalkhi adalah murni klinis. Al-Balkhi dengan terang menyebut bahwa bab demi bab bukunya lebih merupakan petunjuk praktis yang dapat digunakan sebagai pedoman untuk menjaga, mengatur, dan meningkatkan kesehatan mental, bukan untuk menyembuhkan gangguan mental (i'âd al-shihhah). Bahwa sebagian metodenya bermanfaat untuk menyembuhkan gangguan mental tertentu, tidak lantas menggugurkan tujuan utama ditulisnya risalah tersebut. Tujuan utama Al-Balkhi adalah meningkatkan keseimbangan antara tubuh dan jiwa, sebab hanya dengan cara demikian manusia mampu mencapai keadaan sehat Lantas sudah cukupkah dengan sehat semata? Apa sebenarnya yang diinginkan Al-Balkhi dengan pribadi yang sehat? Jawaban dari pertanyaan pertama: tentu tidak cukup, sebab kesehatan bukan tujuan final manusia. Jawaban dari pertanyaan kedua mengandaikan adanya ihwal yang lebih tinggi dari sekadar sehat. Apa itu? Al-Balkhi menyebutnya kebahagiaan duniawi: 
واســتكمل الســـعادة الدنيويـــة, لأن كمــال هــــه

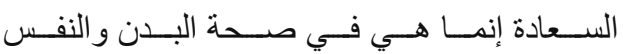

وراحتهمـا

[Dengan langkah-langkah tersebut, maka menjadi sempurna kebahagiaan hidup di dunia, dan itu hanya dapat terpenuhi apabila badan dan jiwa dalam keadaan sehat dan stabil]

Di titik ini, Al-Balkhi membeberkan orientasi positifnya dengan menyebutkan kebahagiaan (al-sa'âdah) sebagai tujuan puncak manusia di dunia. Orientasi positif untuk bahagia merupakan topik sentral pada masa itu. Hal itu didukung oleh karya-karya ilmuwan Muslim yang semasa dengan Al-Balkhi dan secara khusus menulis tentang kebahagiaan, semisal Abu Nashr Al-Farabi (870-950). Kitabnya yang berjudul Risâlat al-Tanbîh ilâ Tahshîl al-Sa'âdah menjadi rujukan penting hingga sekarang. Akan tetapi, berbeda dari AlBalkhi, pendekatan Al-Farabi cenderung filosofis dan masih kuat pengaruh Aristoteles dan Neoplatonismenya. Makanya, tidak salah jika Al-Balkhi dengan penuh percaya diri mengatakan bahwa tidak ada ahli medis sebelum dia yang mengaitkan secara sistematis antara kesehatan badan dan jiwa serta pengaruhnya terhadap kebahagiaan dengan pendekatan kognitif-empiris. Hingga sekarang, kebahagiaan (happiness) merupakan tema sentral yang banyak mendapat perhatian psikolog, terutama di era populernya tren psikologi positif abad ke-21. Bahkan, pionir psikologi positif modern, Martin Seligman menulis buku khusus yang menjelaskan kebahagiaan: Authentic Happiness—sebuah tema yang sudah ditulis Al-Farabi seribuan tahun yang lalu.

Menarik dicermati bahwa Al-Balkhi (juga Al-Farabi) mengasosiasikan kebahagiaan sebagai tujuan puncak yang ingin dicapai oleh manusia di dunia ('ghâyah al-mathlûb fi aldunya). Dalam Mashâlih al-Abdân wa al-Anfus, Al-Balkhi secara mengejutkan-terutama bagi pembela islamisasi psikologi-tidak menulis satu pun frasa yang merujuk pada kebahagiaan ukhrawi. Al-Balkhi tampaknya menyadari bahwa kebahagiaan ukhrawi merupakan domain tasawuf yang menjadi otoritas para sufi. Sedangkan ilmu yang ditekuni Al-Balkhi, dengan metodenya yang empiris, tidak memiliki pretensi untuk mengambil alih otoritas yang dimiliki disiplin ilmu lainnya. Mustahil Al-Balkhi tidak mengetahui, misalnya, kandungan ayat 56 surat Az-Dzariyat dalam Al-Qur'an. Namun, AlBalkhi sama sekali tidak menyinggung ayat tersebut untuk menjustifikasi landasan teoretisnya.

Satu-satunya landasan teologis yang disinggung Al-Balkhi dalam pengantarnya adalah bahwa Allah tidak menurunkan setiap penyakit kecuali selalu disertai obatnya (likulli dâ'i dawâ'un). Seseorang yang mengalami sakit harus percaya bahwa ia akan sembuh karena Allah. Kendati demikian, bukan kepercayaan kepada Allah yang menjadi titik tekan, melainkan kepercayaan untuk sembuh. Pasienpasien Al-Balkhi bahkan ada yang beragama Zoroaster dan tidak mungkin disugesti untuk 
percaya kepada Allah sebagai Zat yang Maha Menyembuhkan. Menghadapi pasien jenis ini, yang dilakukan Al-Balkhi adalah menyugesti pikiran si pasien agar darinya tumbuh keyakinan kuat untuk sembuh dan sehat Di titik ini, Malik Badri tampak berlebihan ketika menyebut AlBalkhi memiliki kontribusi penting dalam pendekatan yang berorientasi pada psikologi Islam (Badri, 2013), sebab keyakinan bahwa semua penyakit dapat sembuh hanya dengan pertolongan Allah sudah pasti tertanam dalam hati setiap kaum muslim, dengan atau tanpa justifikasi psikologi Islam.

Hal itu selaras dengan kesimpulan Mahmud Mishry yang menegaskan bahwa fondasi konsep kesehatan mental Al-Balkhi terletak pada optimisme yang kuat (غلبـــة
التفائـــل عـــن التشـــــائم Orang yang sudah sehat harus tetap menjaga optimisme untuk terus sehat, sementara orang yang terserang penyakit harus menaruh optimisme agar cepat sembuh (Mishry, 2005). Aktivasi pikiran agar selalu optimistis seperti yang anjuran Al-Balkhi jelas merupakan prototipe paling awal dari apa yang kita sebut psikologi positif (positive psychology) sekarang ini. Bukan hanya itu, $\mathrm{Al}-$ Balkhi selalu memberi judul babnya dengan awalan frasa " "meningkatkan"; "mengatur"; "mengelola"; atau "mengupayakan". Al-Balkhi lebih memilih kata tadbîr daripada 'ilâj karena kata yang disebut pertama bersifat positif, sementara yang yang setelahnya bersifat negatif meski tujuannya sama-sama positif.

\section{Gambar 4}

Skema Orientasi Positif Kesehatan Mental Al-Balkhi

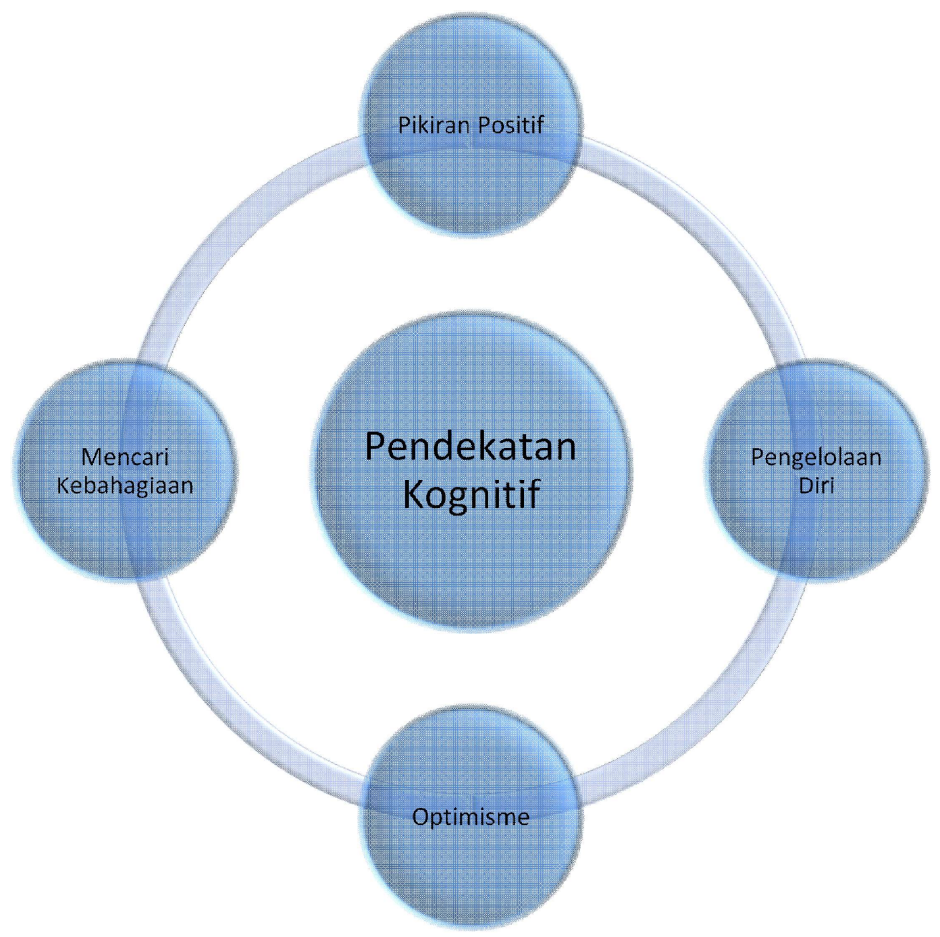


Kampanye Al-Balkhi untuk hidup sehat, selalu berpikir rasional dan positif, serta mengedepankan optimisme telah melampaui kecenderung umum psikologi modern sejak Perang Dunia II. Sebab, Al-Balkhi dalam risalahnya tidak hanya membicarakan metode menyembuhkan sakit mental (i'âdah alshihhah/curing mental illness), tetapi juga telah sampai pada tahap membantu manusia lebih produktif dan hidup bermakna (helping all people to lead more productive and fulfilling lives). Dengan demikian, Al-Balkhi telah memasukkan kesehatan mental dan gangguan mental secara seimbang dalam satu topik kajian yang dalam psikologi Barat cenderung terpisah (Seligman, 2002). Meski Al-Balkhi tidak secara lengkap mengeksplorasi poin terakhir dari tiga tujuan utama psikologi (seperti yang disinggung Seligman di atas), setidaknya Al-Balkhi telah berhasil memenuhi dua yang pertama, yaitu menyembuhkan yang sakit dan meningkatkan produktivitas yang sehat. Dan pencapaian ini sungguh sangat maju untuk ukuran abad ke-9.

\section{Simpulan}

Al-Balkhi lewat Mashâlih al-Abdân wa alAnfus telah memberikan pemikiran yang orisinal tentang terapi kognitif yang berorientasi positif; yaitu dengan menjaga pikiran dari tekanan negatif dengan cara menghadirkan pikiran positif (al-'ilâj bi aldhid). Al-Balkhi juga menegaskan bahwa setiap penyakit memiliki obat; dan obat dari hampir seluruh penyakit mental adalah bersumber dari pikiran manusia itu sendiri. Dengan menjaga pikiran tetap konsisten rasional dan sehat, manusia akan merasakan kebahagiaan. Asupan utama yang dibutuhkan oleh jiwa agar menjadi kuat dan sehat adalah pengetahuan yang seimbang dan pikiran yang positif dengan cara membuang prasangka negatif dan misinformasi yang tidak perlu.

Dengan metode empiris yang dipadukan dengan terapi spiritual (meski sebatas yakin bahwa Allah tidak menurunkan penyakit kecuali bersama dengan obat penawarnya), $\mathrm{Al}-$ Balkhi-sebagaimana diakui Haque dan Badri-merupakan pionir terapi kognitif dari abad keemasan Islam yang memiliki banyak kemiripan dengan terapi kognitif modern. Kendati demikian, Al-Balkhi tidak berbicara spiritualitas dan doktrin-doktrin Islam secara khusus di dalam risalahnya, sehingga pendekatannya tidak dapat dijadikan justifikasi apa pun bagi psikologi Islam-kecuali sebatas fakta bahwa Al-Balkhi adalah seorang ilmuwan muslim yang, sebagaimana keyakinan seluruh umat Islam, memegang teguh keimanan bahwa sumber segala kesembuhan semata berasal dari Yang Mahakuasa.

\section{Saran}

Kendati orisinal, beberapa teori yang ditulis dalam risalahnya, tidak seluruhnya dapat dipuji dan diikuti di zaman sekarang. Teori AlBalkhi tentang kesehatan badan masih menggunakan paradigma kedokteran Yunani, terutama melalui warisan Hippocrates dan 
Galen, meskipun juga terdapat sentuhan Islam. Namun, temuan kedokteran modern telah jauh lebih maju dan beberapa teori arus utama yang berasal dari Hippocrates maupun Galen terbukti tidak relevan dengan sekarang. Dengan demikian, bagi peneliti selanjutnya, penting untuk melakukan telaah kritis terhadap konsep kesehatan badan Al-Balkhi dengan pendekatan teori dan praktik kedokteran mutakhir agar apa yang disebut sebagai "keseimbangan badan dan jiwa" tidak anakronistis dan relavan untuk masa-masa yang akan datang.

Implikasi teoretis yang muncul dari penelitian ini setidaknya ada dua, (a) teori kognitif Al-Balkhi jauh lebih sesuai dengan sains modern ketimbang teori kesehatan badannya, dan (b) tidak setiap pendekatan empiris berarti sekuler dan harus diislamkan, karena faktanya Al-Balkhi tidak mengutip satu ayat atau hadis pun dalam risalahnya. Dan juga tidak ada doktrin-doktrin Islam yang dirujuknya. Pendekatan Al-Balkhi murni empiris-dan itu bisa lahir dari seorang muslim. Dengan demikian, paradigma keilmuan AlBalkhi dapat dijadikan titik tolak untuk mendefinisikan ulang apa dan bagaimanaurgensi-"psikologi Islam".

\section{Referensi}

Al-Balkhi, A. Z. S. (2005). Mashâlih al-Abdân wa al-Anfus. Ma'had al-Mahthûthât al'Arabiyyah.

Alex Linley, P., Joseph, S., Harrington, S., \& Wood, A. M. (2006). Positive psychology: Past, present, and (possible) future. The Journal of Positive Psychology, 1(1), 3-
16. https://doi.org/10.1080/ 17439760500372796

Asch, M. (2002). Textbook of Cognitive Psychology. IVY Publishing House.

Awaad, R., \& Ali, S. (2015). Obsessional disorders in al-Balkhi2 s 9th century treatise: Sustenance of the body and soul. Journal of Affective Disorders, 180, 185-189. h ttps: / / doi.org/10.1016/ j.jad.2015.03.003

Awaad, R., \& Ali, S. (2016). A modern conceptualization of phobia in al-Balkhi's 9th century treatise: Sustenance of the body and soul. Journal of Anxiety Disorders, 37, 89-93. https://doi.org/ 10.1016/j.janxdis.2015.11.003

Badri, M. B. (2013). Abu zayd alBalkhi's sustenance of the soul: The cognitive behavior therapy of a ninth century physician. International Institute of Islamic Thought. https://doi.org/ $10.2307 /$ j.ctvh4zfhk

Boals, A., VanDellen, M. R., \& Banks, J. B. (2011). The relationship between self-control and health: The mediating effect of avoidant coping. Psychology \& Health, 26(8), 1049-1062. https://doi.org/ $10.1080 / 08870446.2010 .529139$

Carr, A. (2004). Positive psychology: The science of happiness and human strengths. Brunner-Routledge.

Deuraseh, N., \& Talib, M. A. (2005). Mental health in islamic medical tradition. The International Medical Journal, 4(2), 76-79.

Haque, A. (2004). Psychology from islamic perspective: Contributions of early muslim scholars and challenges to contemporary muslim psychologists. Journal of Religion and Health, 43(4), 357-377. https://doi.org/10.1007/ s10943-004-4302-z

Hein, S. F., \& Austin, W. J. (2001). Empirical and hermeneutic approaches to phenomenological research in psychology: A comparison. Psychological Methods, 6(1), 317.https://doi.org/10.1037/1082-989X.6.1.3 
Herrman, H. (2005). Promoting mental health: Concepts, emerging evidence, practice. WHO. https://doi.org/https:// apps.who.int/iris/handle/10665/42940

Hope, T. (2011). Cognitive therapy and positive psychology combined: A promising approach to the enhancement of happiness. In Julian Savulescu, et al. (ed.), Enhacing Human Capacities. Blackwell Publishing Ltd.

Kafle, N. P. (2013). Hermeneutic phenomenological research method simplified. Bodhi: An Interdisciplinary Journal, 5(1), 181-200. https://doi.org/ 10.3126/bodhi.v5i1.8053

Kertanegara, M. (2014). Essentials of Islamic epistemology: A philoshopical inquiry into the foundation of knowledge. UBD Press.

Maddux, J. E. (2002). Stopping the madness: Positive psychology and the deconstruction of the illness ideology and the DSM. In Snyder \& Lopez (ed.), Handbook of Positive Psychology. Oxford University Press.

Mishry, M. (2005). Fî turâtsi hifz al-shihhati. In Abu Zayd Sahl Al-Balkhi, Mashâlih alAbdân wa al-Anfus. Ma'had alMahthûthât al-'Arabiyyah.
Mohamed, W. M. (2012). Arab and muslim contribution to modern neuroscience.

Musfihin, M. (2019). Keseimbangan badan dan jiwa perspektif Abu Zaid Al-Balkhi. Jurnal Studia Insania, 7(1), 66. https://doi.org/ 10.18592/jsi.v7i1.2632

Nasr, S. H. (1970). Science and civilization in Islam. Harvard University Press.

Seligman, M. (2002). Positive psychology, positive prevention, and positive therapy. In Snyder \& Lopez (ed.), Handbook of Positive Psychology. Oxford University Press.

Thaha, Z. B. (2011). 'Ilm al-Nafs fi al-Turâts al'Araby al-Islâmy. Syabakah al-'Ulûm alNafsiyyah al-Aarabiyyah.

Yaacob, N. R. N. (2013). Cognitive therapy approach from Islamic psycho-spiritual conception. Procedia - Social and Behavioral Sciences, 97, 182-187. https:/ /doi.org/10.1016/j.sbspro.2013.10.220

York Al-Karam, C. (2018). Islamic psychology: Towards a 21st century definition and conceptual framework. Journal of Islamic Ethics, 2(1-2), 97-109. https://doi.org/ $10.1163 / 24685542-12340020$

Received 20 July 2020 Revised 5 December 2020 Accepted 31 July 2021 